\title{
Radio Analytical Nondestructive Technique in Performance Evaluation of Organic Base Ion Exchange Resins Purolite NRW-6000 and Duolite A-378
}

\author{
P. U. Singare \\ Department of Chemistry, Bhavan's College, Munshi Nagar, Andheri (West), Mumbai 400 058, India \\ Tel No. + 9122 26256451/ 52; Fax No. + 912226256453 \\ ${ }^{*}$ E-mail address: pravinsingare@gmail.com
}

\begin{abstract}
Nondestructive radioanalytical technique using short lived isotopes ${ }^{131} \mathrm{I}$ and ${ }^{82} \mathrm{Br}$ was used as tracers to study the kinetics of iodide and bromide ion-isotopic exchange reactions. The kinetic data so obtained was used to evaluate the performance of organic base anion exchange resins Purolite NRW6000 and Duolite A-378. It was observed that for iodide ion-isotopic exchange reaction performed at $40.0^{\circ} \mathrm{C}$ using $1.000 \mathrm{~g}$ of ion exchange resins and $0.003 \mathrm{~mol} / \mathrm{L}$ labeled iodide ion solution, the values of specific reaction rate $\left(\mathrm{min}^{-1}\right)$, amount of iodide ion exchanged $(\mathrm{mmol})$, initial rate of iodide ion exchange $(\mathrm{mmol} / \mathrm{min})$ and $\log \mathrm{K}_{\mathrm{d}}$ were calculated as $0.332,0.582,0.193$ and 16.2 respectively for Purolite NRW-6000 resin, which was higher than the respective values of $0.210,0.421,0.088$ and 14.7 as that obtained for Duolite A-378 resins. Also at a constant temperature of $40.0{ }^{\circ} \mathrm{C}$, as the concentration of labeled iodide ion solution increases from $0.001 \mathrm{~mol} / \mathrm{L}$ to $0.004 \mathrm{~mol} / \mathrm{L}$, the percentage of iodide ions exchanged increases from $74.68 \%$ to $79.48 \%$ using Purolite NRW-6000 resins and from $52.30 \%$ to $58.90 \%$ using Duolite A-378 resins. The overall results indicate superior performance of Purolite NRW-6000 resins over Duolite A-378 resins under identical operational parameters. It is expected here that the present technique can be extended further for characterization of different ion exchange resins which will further help in the selection of those reins for the specific industrial application.
\end{abstract}

Keywords: anion exchange; resins; Purolite NRW-6000; Duolite A-378; isotopic exchange tracer isotopes; ${ }^{131} \mathrm{I} ;{ }^{82} \mathrm{Br}$; nondestructive technique

\section{INTRODUCTION}

Ion exchange method is one of the most widely used both in the nuclear industry and the conventional chemical industry for the purification, separation and partitioning of particular non-radioactive and radioactive species with different chemical properties. As far as nuclear industry is concerned a wide range of ion exchange materials are available for the treatment of liquid radioactive waste. These materials are available in a variety of forms and have widely differing chemical and physical properties. Ion exchange is used for processing liquid effluents in nearly all phases of the nuclear fuel cycle, including the early stages of uranium ore treatments, the chemical control of primary circuit coolants during nuclear power 
plant operations and polishing water effluents at spent fuel reprocessing plants. Inorganic ion exchangers often have the advantage of a much greater selectivity than organic resins for certain radiologically important species, such as caesium and strontium.

These inorganic materials may also prove to have advantages with respect to immobilization and final disposal when compared with organic ion exchangers. However, in nuclear power plant operations the currently available inorganic exchangers cannot entirely replace conventional organic ion exchange resins, especially in high purity water applications or in operations in which the system chemistry must be controlled through the maintenance of dissolved species such as lithium ions or boric acid [1].

Efforts to develop new organic ion exchangers for their specific industrial applications are continuing $[2,3]$ and various aspects of ion exchange technologies have been continuously studied to improve the efficiency and economy of their application in various technological applications [4-7]. However, for proper selection of ion exchange resin, it is essential to have adequate knowledge regarding their physical and chemical properties, which forms the complementary part of resin characterization study.

Generally the selected ion exchange materials must be compatible with the chemical nature of the liquid waste such as $\mathrm{pH}$, type of ionic species present as well as the operating parameters, in particular temperature.

Although there are different methods reported in the literature for evaluation and characterization of ion exchange resins [8-11], but the isotopic tracers technique as one of the non destructive radio analytical technique offer several advantages such as high detection sensitivity, capability of in-situ detection, limited memory effects and physico-chemical compatibility with the material under study $[12,13]$.

Considering the extensive technological application of radioactive tracers, in the present investigation, attempts are made to apply the same technique to study the kinetics of ionisotopic exchange reactions in Purolite NRW-6000 (nuclear grade) and Duolite A-378 (nonnuclear grade) anion exchange resins. It is expected that the kinetics data obtained here will not only be used in characterization of these resins but also in standardization of the process parameters for their efficient industrial application.

\section{EXPERIMENTAL}

\section{1. Conditioning of ion exchange resins}

Purolite NRW-6000 is a nuclear grade Type I porous gel strong base anion exchange resin in hydroxide form (supplied by Purolite International India Private Limited, Pune, India) while Duolite A-378 is a weak base anion exchange resin in hydroxide form (supplied by Auchtel Products Ltd., Mumbai, India). Details regarding the properties of the resins used are given in Table 1. These resins were converted separately in to iodide / bromide form by treatment with $10 \% \mathrm{KI} / \mathrm{KBr}$ solution in a conditioning column which is adjusted at the flow rate as $1 \mathrm{~mL} / \mathrm{min}$.

The resins were then washed with double distilled water, until the washings were free from iodide/bromide ions as tested by $\mathrm{AgNO}_{3}$ solution. These resins in bromide and iodide form were then dried separately over $\mathrm{P}_{2} \mathrm{O}_{5}$ in desiccators at room temperature. 
Table 1. Properties of ion exchange resins.

\begin{tabular}{|c|c|c|c|c|c|c|c|}
\hline $\begin{array}{c}\text { Ion } \\
\text { exchange } \\
\text { resin }\end{array}$ & Matrix & $\begin{array}{c}\text { Functional } \\
\text { Group }\end{array}$ & $\begin{array}{c}\text { Mean } \\
\text { particle } \\
\text { Size } \\
(\mathrm{mm})\end{array}$ & $\begin{array}{c}\text { Moisture } \\
\text { content } \\
(\%)\end{array}$ & $\begin{array}{c}\text { Operating } \\
\mathrm{pH}\end{array}$ & $\begin{array}{c}\text { Maximum } \\
\text { operating } \\
\text { temperature } \\
\left({ }^{\circ} \mathrm{C}\right)\end{array}$ & $\begin{array}{c}\text { Total } \\
\text { exchange } \\
\text { capacity } \\
(\mathrm{mEq} . / \mathrm{mL})\end{array}$ \\
\hline $\begin{array}{c}\text { Purolite } \\
\text { NRW- } \\
6000\end{array}$ & $\begin{array}{c}\text { Polystyrene } \\
\text { crosslinked } \\
\text { with divinyl } \\
\text { benzene }\end{array}$ & $\begin{array}{c}\text { Quaternary } \\
\text { ammonium }\end{array}$ & 0.63 & 60 & $0-14$ & 60 & 1.1 \\
\hline $\begin{array}{c}\text { Duolite } \\
\text { A-378 }\end{array}$ & Polystyrene & $\begin{array}{c}\text { Tertiary } \\
\text { Ammonium }\end{array}$ & 0.70 & 50 & $0-7$ & 60 & 1.3 \\
\hline
\end{tabular}

\section{2. Radioactive Tracer Isotopes}

The radioisotope ${ }^{131} \mathrm{I}$ and ${ }^{82} \mathrm{Br}$ used in the present experimental work was obtained from Board of Radiation and Isotope Technology (BRIT), Mumbai, India. Details regarding the isotopes used in the present experimental work are given in Table 2.

Table 2. Properties of ${ }^{131} \mathrm{I}$ and ${ }^{82} \mathrm{Br}$ tracer isotopes [12].

\begin{tabular}{|c|c|c|c|c|c|}
\hline Isotopes & Half-life & $\begin{array}{c}\text { Radioactivity } \\
/ \mathrm{mCi}\end{array}$ & $\begin{array}{c}\gamma \text { - energy } \\
/ \mathrm{MeV}\end{array}$ & $\begin{array}{c}\text { Chemical } \\
\text { form }\end{array}$ & $\begin{array}{c}\text { Physical } \\
\text { form }\end{array}$ \\
\hline${ }^{131} \mathrm{I}$ & $8.04 \mathrm{~d}$ & 5 & 0.36 & Iodide* & Aqueous \\
\hline${ }^{82} \mathrm{Br}$ & $36 \mathrm{~h}$ & 5 & 0.55 & Bromide** & Aqueous \\
\hline
\end{tabular}

* Sodium iodide in dilute sodium sulphate.

** Ammonium bromide in dilute ammonium hydroxide.

\subsection{Study on kinetics of iodide ion-isotopic exchange reaction}

In a stoppered bottle $250 \mathrm{~mL}(V)$ of $0.001 \mathrm{~mol} / \mathrm{L}$ iodide ion solution was labeled with diluted ${ }^{131}$ I radioactive solution using a micro syringe, such that $1.0 \mathrm{~mL}$ of labeled solution has a radioactivity of around 15,000 cpm (counts per minute) when measured with $\gamma$-ray spectrometer having NaI (Tl) scintillation detector. Since only about 50-100 $\mu \mathrm{L}$ of the radioactive iodide ion solution was required for labeling the solution, its concentration will remain unchanged, which was further confirmed by potentiometer titration against $\mathrm{AgNO}_{3}$ solution. The above labeled solution of known initial activity $\left(A_{i}\right)$ was kept in a thermostat adjusted to $30.0{ }^{\circ} \mathrm{C}$. The swelled and conditioned dry ion exchange resins in iodide form weighing exactly $1.000 \mathrm{~g}(\mathrm{~m})$ were transferred quickly into this labeled solution which was vigorously stirred by using mechanical stirrer and the activity in cpm of $1.0 \mathrm{~mL}$ of solution was measured. The solution was transferred back to the same bottle containing labeled solution after measuring activity. The iodide ion-isotopic exchange reaction can be represented as:

$$
\mathrm{R}-\mathrm{I}+\mathrm{I}^{*-}{ }_{(\text {aq. })} \rightleftharpoons \mathrm{R}-\mathrm{I}^{*}+\mathrm{I}^{-}{ }_{\text {(aq.) }}
$$

here R-I represents ion exchange resin in iodide form; $\mathrm{I}^{*^{-}}{ }_{(\text {aq. }}$ represents aqueous iodide ion solution labeled with ${ }^{131}$ I radiotracer isotope [23-25]. The activity of solution was measured at 
a fixed interval of every $2.0 \mathrm{~min}$. The final activity $\left(A_{f}\right)$ of the solution was also measured after $3 \mathrm{~h}$ which was sufficient time to attain the equilibrium [14-18,23,24]. The activity measured at various time intervals was corrected for background counts. Similar experiments were carried out by equilibrating separately $1.000 \mathrm{~g}$ of ion exchange resin in iodide form with labeled iodide ion solution of four different concentrations ranging up to $0.004 \mathrm{~mol} / \mathrm{L}$ at a constant temperature of $30.0{ }^{\circ} \mathrm{C}$. The same experimental sets were repeated for higher temperatures up to $45.0^{\circ} \mathrm{C}$.

\section{4. Study on kinetics of bromide ion-isotopic exchange reaction}

The experiment was also performed to study the kinetics of bromide ion- isotopic exchange reaction by equilibrating $1.000 \mathrm{~g}$ of ion exchange resin in bromide form with labeled bromide ion solution in the same concentration and temperature range as above. The labeling of bromide ion solution was done by using ${ }^{82} \mathrm{Br}$ as a radioactive tracer isotope for which the same procedure as explained above was followed. The bromide ion-isotopic exchange reaction can be represented as:

$$
\mathrm{R}-\mathrm{Br}+\mathrm{Br}^{*{ }^{-}}{ }_{\text {(aq.) }} \rightleftharpoons \mathrm{R}-\mathrm{Br}^{*}+\mathrm{Br}^{-}{ }_{(\text {aq. })}
$$

here $\mathrm{R}-\mathrm{Br}$ represents ion exchange resin in bromide form; $\mathrm{Br}^{*-}{ }_{(\mathrm{aq} .)}$ represents aqueous bromide ion solution labeled with ${ }^{82} \mathrm{Br}$ radiotracer isotope [23-25].

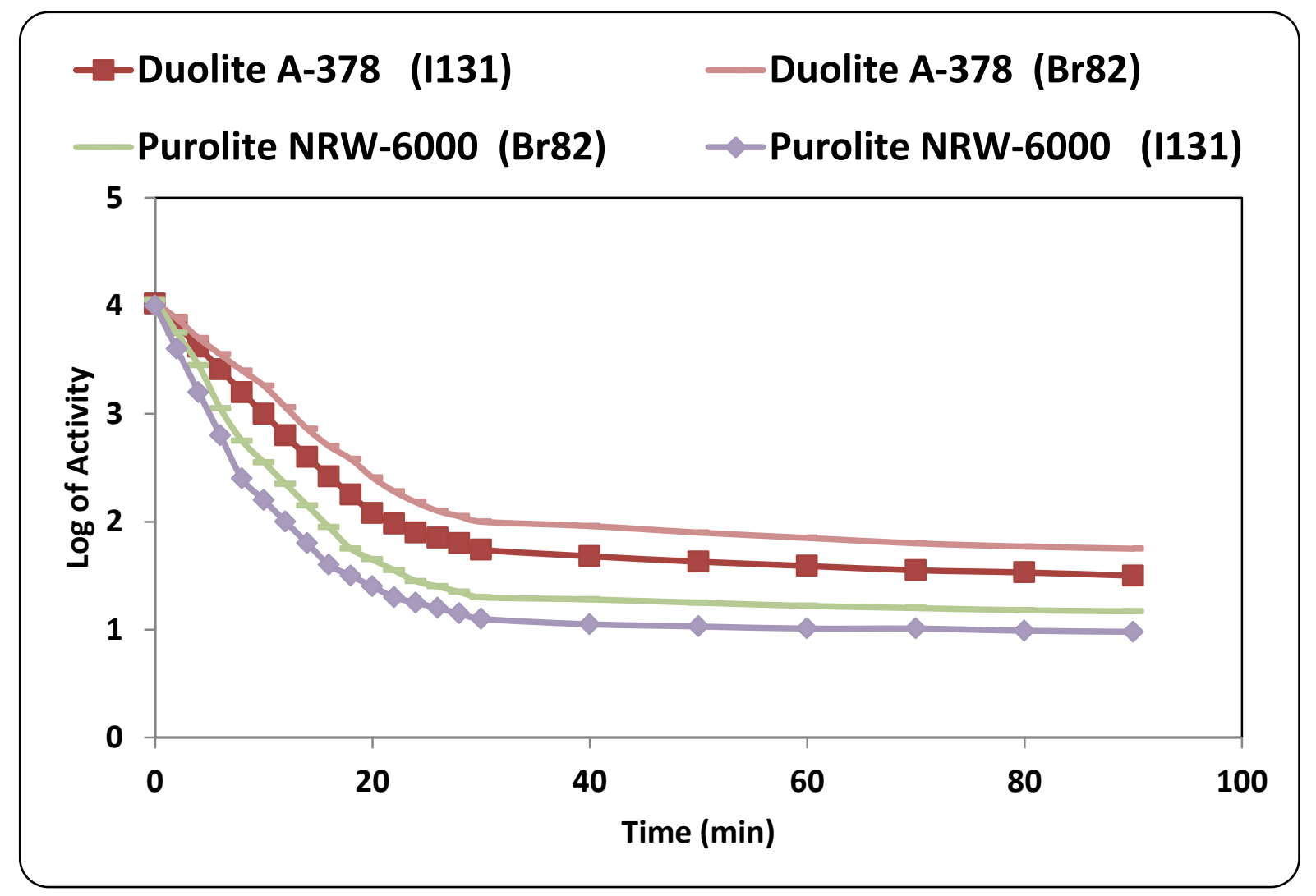

Figure 1. Kinetics of Ion-Isotopic Exchange Reactions.

Amount of ion exchange resin $=1.000 \mathrm{~g}$, Concentration of labeled exchangeable ionic solution $=0.003 \mathrm{~mol} / \mathrm{L}$, Volume of labeled ionic solution $=250 \mathrm{~mL}$, Temperature $=40.0^{\circ} \mathrm{C}$. 
Table 3. Concentration effect on Ion-Isotopic Exchange Reactions.

Amount of ion exchange resin $=1.000 \mathrm{~g}$

Volume of labeled ionic solution $=250 \mathrm{~mL}$

\begin{tabular}{|c|c|c|c|c|c|c|}
\hline \multicolumn{7}{|c|}{ Temperature $=40.0^{\circ} \mathrm{C}$} \\
\hline$\stackrel{8}{8}$ & $\stackrel{8}{8}$ & 8 & 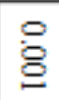 & \multicolumn{3}{|c|}{$\begin{array}{l}\text { Concentration of ionic solution } \\
(\mathrm{mol})\end{array}$} \\
\hline $\bar{\S}$ & $\underset{\substack{\mathrm{g} \\
\mathrm{g}}}{\circ}$ & 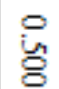 & 莕 & \multicolumn{3}{|c|}{$\begin{array}{l}\text { Amount of ions in } 250 \mathrm{~mL} \text { solution } \\
(\mathrm{mmol})\end{array}$} \\
\hline 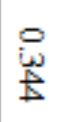 & 岕 & 岕 & 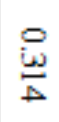 & $\begin{array}{l}\text { Specific reaction rate of } \\
\text { rapid process } \\
\text { min }^{-1}\end{array}$ & \multirow{4}{*}{ 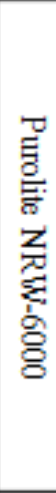 } & \multirow{8}{*}{ 象 } \\
\hline : & 通 & $\stackrel{\mathscr{\Psi}}{\mathscr{O}}$ & $\underset{\infty}{\infty}$ & $\begin{array}{l}\text { Amount of iodide ion } \\
\text { exchanged (mmol) }\end{array}$ & & \\
\hline$\stackrel{\circ}{\stackrel{\sim}{\mathcal{U}}}$ & $\stackrel{0}{0}$ & 总 & 怘 & $\begin{array}{l}\text { Initial rate of iodide ion } \\
\text { exchange (mmol/min) }\end{array}$ & & \\
\hline$\underset{i}{-1}$ & $\bar{a}$ & $\bar{v}$ & 志 & $\log \mathrm{K}_{\triangleleft}$ & & \\
\hline$\stackrel{\circ}{\stackrel{0}{6}}$ & $\stackrel{\stackrel{0}{0}}{\circ}$ & $\stackrel{\wp}{\circ}$ & 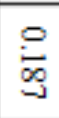 & $\begin{array}{l}\text { Specific reaction rate of } \\
\text { rapid process } \\
\text { min }^{-1}\end{array}$ & \multirow{4}{*}{ 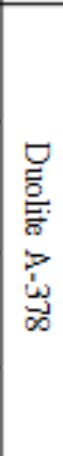 } & \\
\hline : & $\stackrel{8}{\mathrm{E}}$ & $\stackrel{\leftrightarrow}{\mathscr{心}}$ & $\stackrel{\circ}{\omega}$ & $\begin{array}{l}\text { Amount of iodide ion } \\
\text { exchanged } \\
\text { (mmol) }\end{array}$ & & \\
\hline$\stackrel{\circ}{\mathrm{N}}$ & $\stackrel{\mathscr{\mathscr { D }}}{\infty}$ & 怘 & $\stackrel{8}{8}$ & $\begin{array}{l}\text { Initial rate of iodide ion } \\
\text { exchanged (mmol/min) }\end{array}$ & & \\
\hline$\vec{b}$ & $\underset{-}{\Phi}$ & $\breve{\omega}_{\alpha}$ & $\underbrace{N}_{-j}$ & $\log \mathrm{K}_{s}$ & & \\
\hline 递 & 怘 & $\stackrel{\stackrel{P}{\mathcal{U}}}{\mathrm{U}}$ & 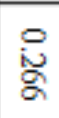 & $\begin{array}{l}\text { Specific reaction rate of } \\
\text { rapid process } \\
\text { min }^{-1}\end{array}$ & \multirow{4}{*}{ 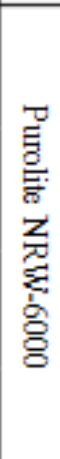 } & \multirow{8}{*}{ 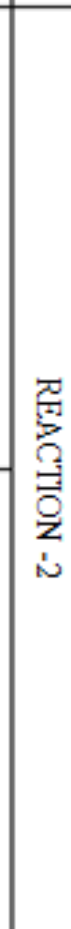 } \\
\hline$\stackrel{8}{\mathrm{U}}$ & 㥕 & $\stackrel{P}{\stackrel{0}{E}}$ & $\stackrel{\circ}{\infty}$ & $\begin{array}{l}\text { Amount of bromide ion } \\
\text { exchanged } \\
\text { (mmol) }\end{array}$ & & \\
\hline 通 & $\stackrel{0}{\mathrm{E}}$ & 8 & 8 & $\begin{array}{l}\text { Initial rate of bromide ion } \\
\text { exchange (mmol/min) }\end{array}$ & & \\
\hline$\Xi_{i}$ & $\underset{\infty}{\bullet}$ & w & $\underbrace{\infty}_{-1}$ & $\log \mathrm{K}_{\diamond}$ & & \\
\hline$\stackrel{\circ}{\stackrel{0}{3}}$ & $\frac{\circ}{2}$ & $\frac{0}{8}$ & $\stackrel{\circ}{\breve{s}}$ & $\begin{array}{l}\text { Specific reaction rate of } \\
\text { rapid process } \\
\text { min }^{-1}\end{array}$ & \multirow{4}{*}{ 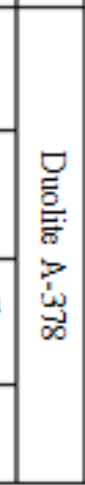 } & \\
\hline$\stackrel{\circ}{\stackrel{\circ}{心}}$ & 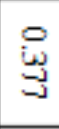 & $\begin{array}{l}8 \\
\text { E }\end{array}$ & $\stackrel{\circ}{\stackrel{N}{0}}$ & $\begin{array}{l}\text { Amount of bromide ion } \\
\text { exchanged } \\
\text { (mmol) }\end{array}$ & & \\
\hline$\stackrel{\mathscr{D}}{\infty}$ & 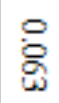 & $\stackrel{\varrho}{\mathscr{G}}$ & $\stackrel{8}{\varrho}$ & $\begin{array}{l}\text { Initial rate of bromide ion } \\
\text { exchange (mmol/min) }\end{array}$ & & \\
\hline$\because$ & $\underbrace{\infty}_{-\infty}$ & $\stackrel{\infty}{-}$ & $\vec{\alpha}$ & $\log \mathrm{K}_{d}$ & & \\
\hline
\end{tabular}


Table 4. Temperature effect on Ion-Isotopic Exchange Reactions. Amount of ion exchange resin $=1.000 \mathrm{~g}$

Concentration of labeled exchangeable ionic solution $=0.003 \mathrm{~mol} / \mathrm{L}$

Volume of labeled ionic solution $=250 \mathrm{~mL}$

Amount of exchangeable ions in $250 \mathrm{~mL}$ labeled solution $=0.750 \mathrm{mmol}$

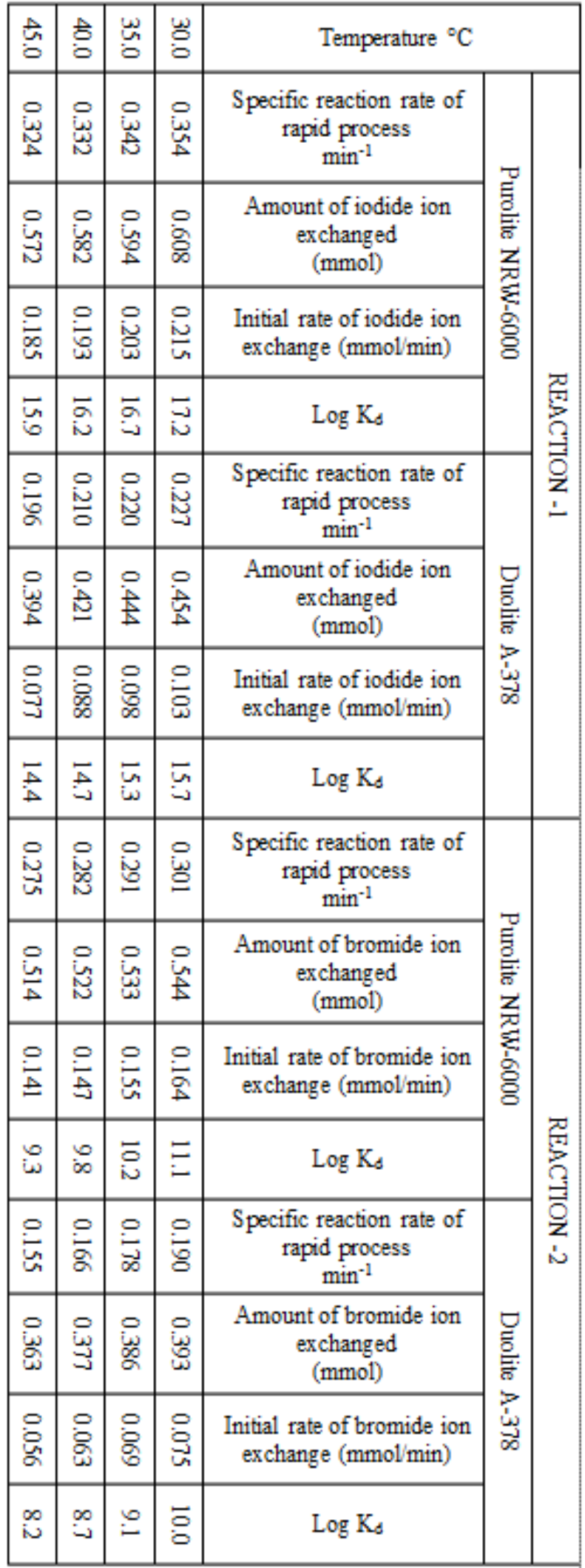




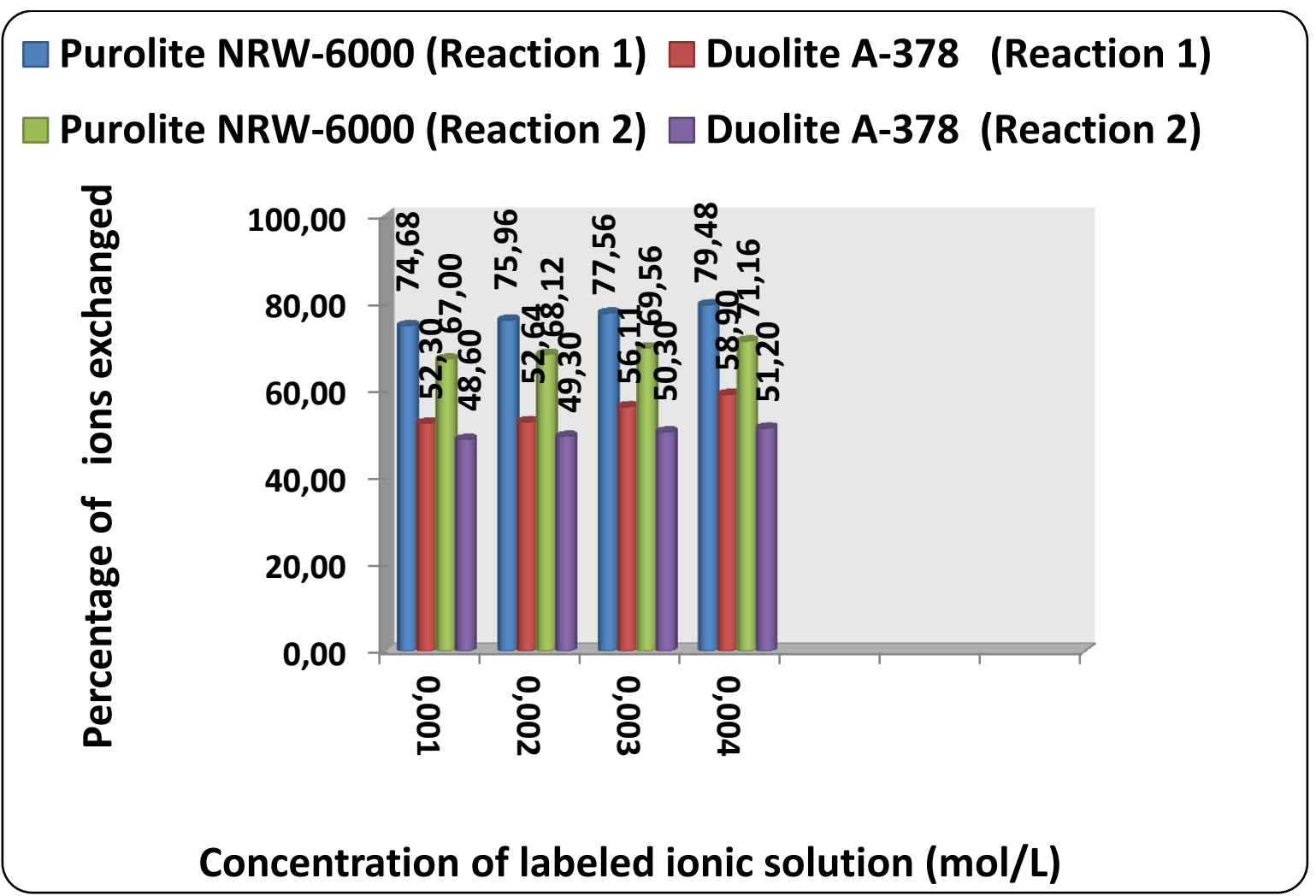

Figure 2. Variation in Percentage Ions Exchanged with Concentration of Labeled Ionic Solution. Amount of ion exchange resin $=1.000 \mathrm{~g}$, Volume of labeled ionic solution $=250 \mathrm{~mL}$, Temperature $=40.0^{\circ} \mathrm{C}$.

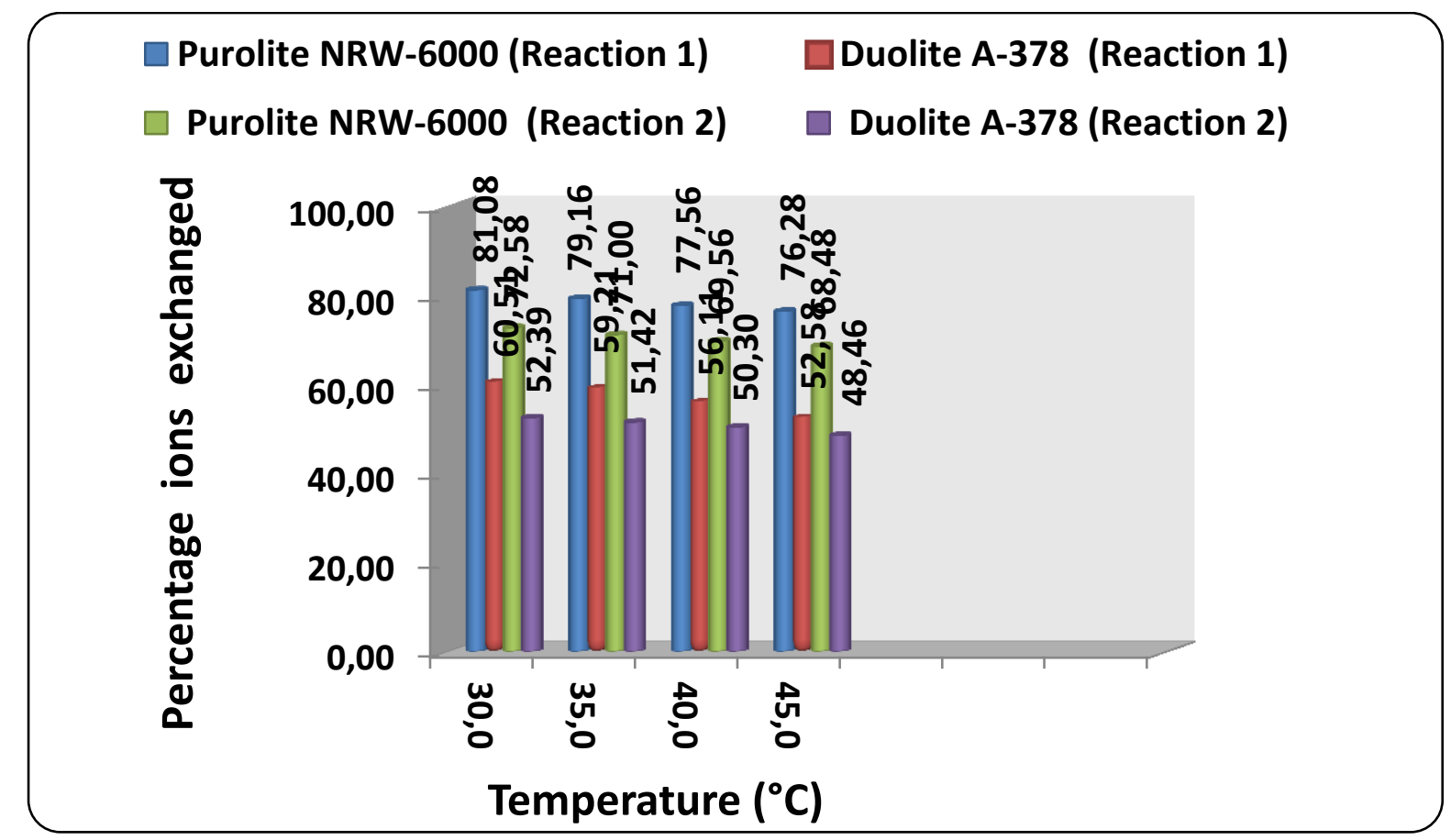

Figure 3. Variation in Percentage Ions Exchanged with Temperature of Labeled Ionic Solution. Amount of ion exchange resin $=1.000 \mathrm{~g}$, Concentration of labeled exchangeable ionic solution $=0.003 \mathrm{~mol} / \mathrm{L}$, Volume of labeled ionic solution $=250 \mathrm{~mL}$, Amount of exchangeable ions in $250 \mathrm{~mL}$ labeled solution $=0.750$ mmol. 


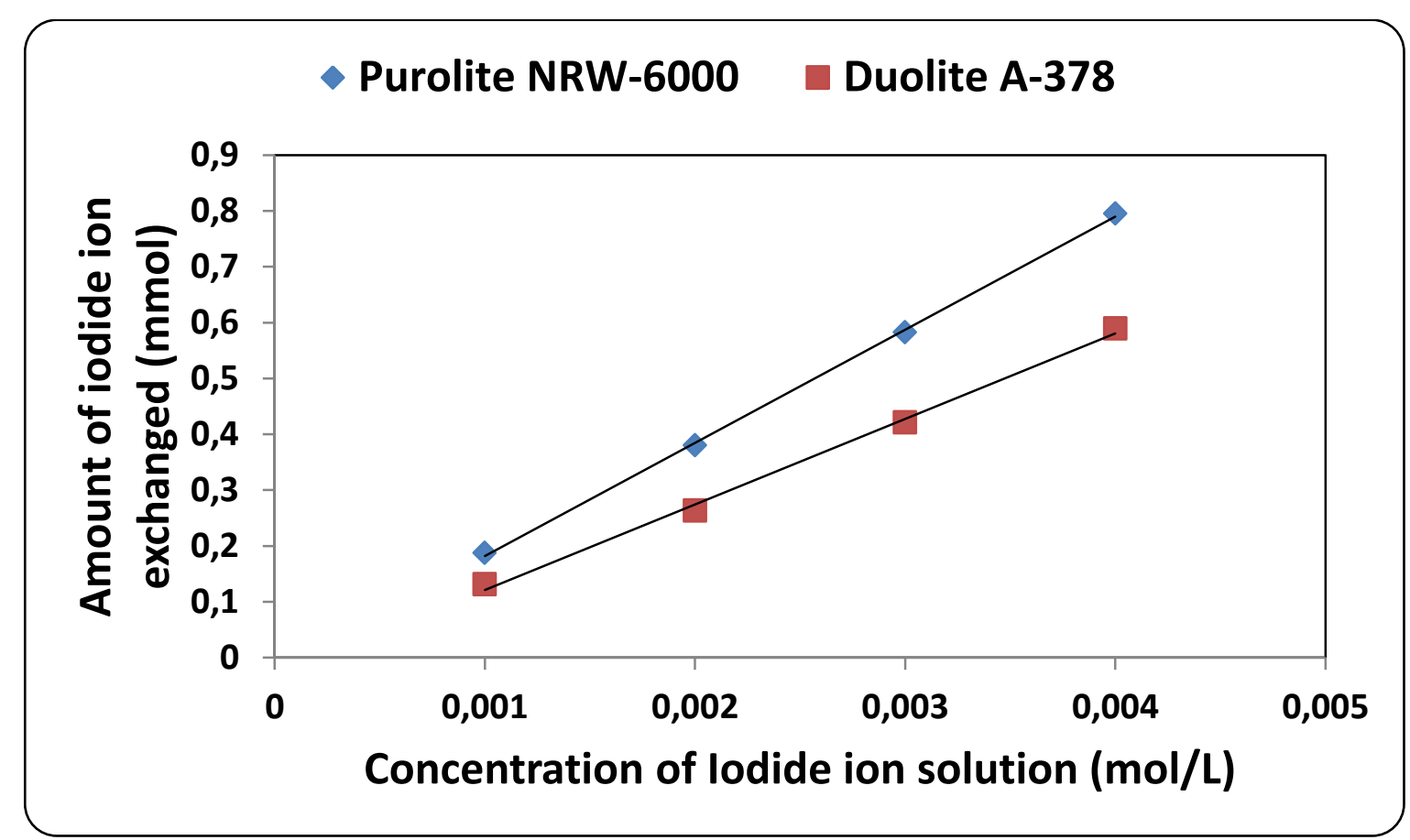

Figure 4. Correlation between concentration of iodide ion solution and amount of iodide ion exchanged.

Amount of ion exchange resin $=1.000 \mathrm{~g}$, Volume of labeled ionic solution $=250 \mathrm{~mL}$, Temperature $=40.0{ }^{\circ} \mathrm{C}$ Correlation coefficient (r) for Purolite NRW-6000 $=0.9998$

Correlation coefficient (r) for Duolite A-378 $=0.9986$

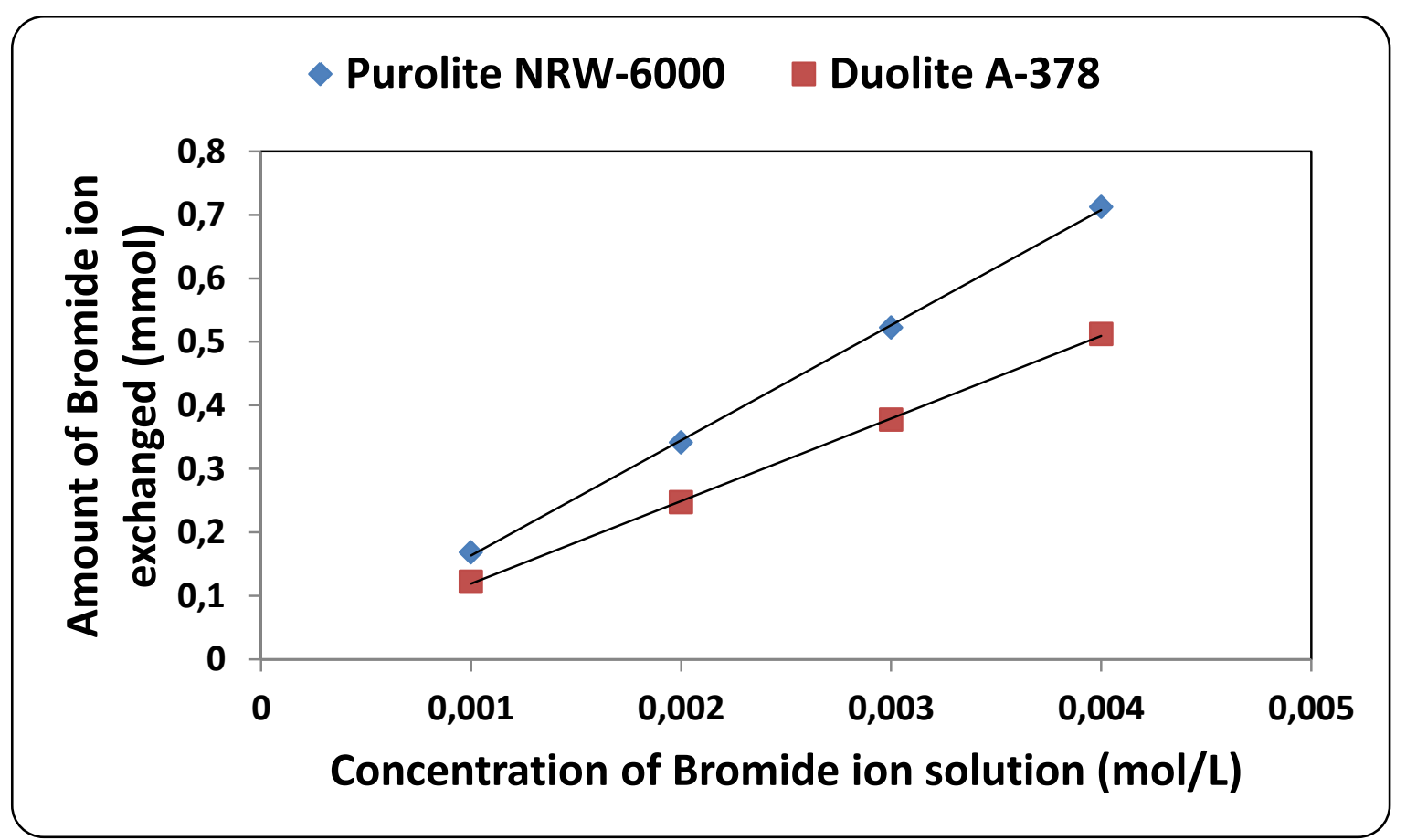

Figure 5. Correlation between concentration of bromide ion solution and amount of bromide ion exchanged.

Amount of ion exchange resin $=1.000 \mathrm{~g}$, Volume of labeled ionic solution $=250 \mathrm{~mL}$, Temperature $=40.0^{\circ} \mathrm{C}$

Correlation coefficient (r) for Purolite NRW-6000 $=0.9998$

Correlation coefficient (r) for Duolite A-378 $=0.9999$ 


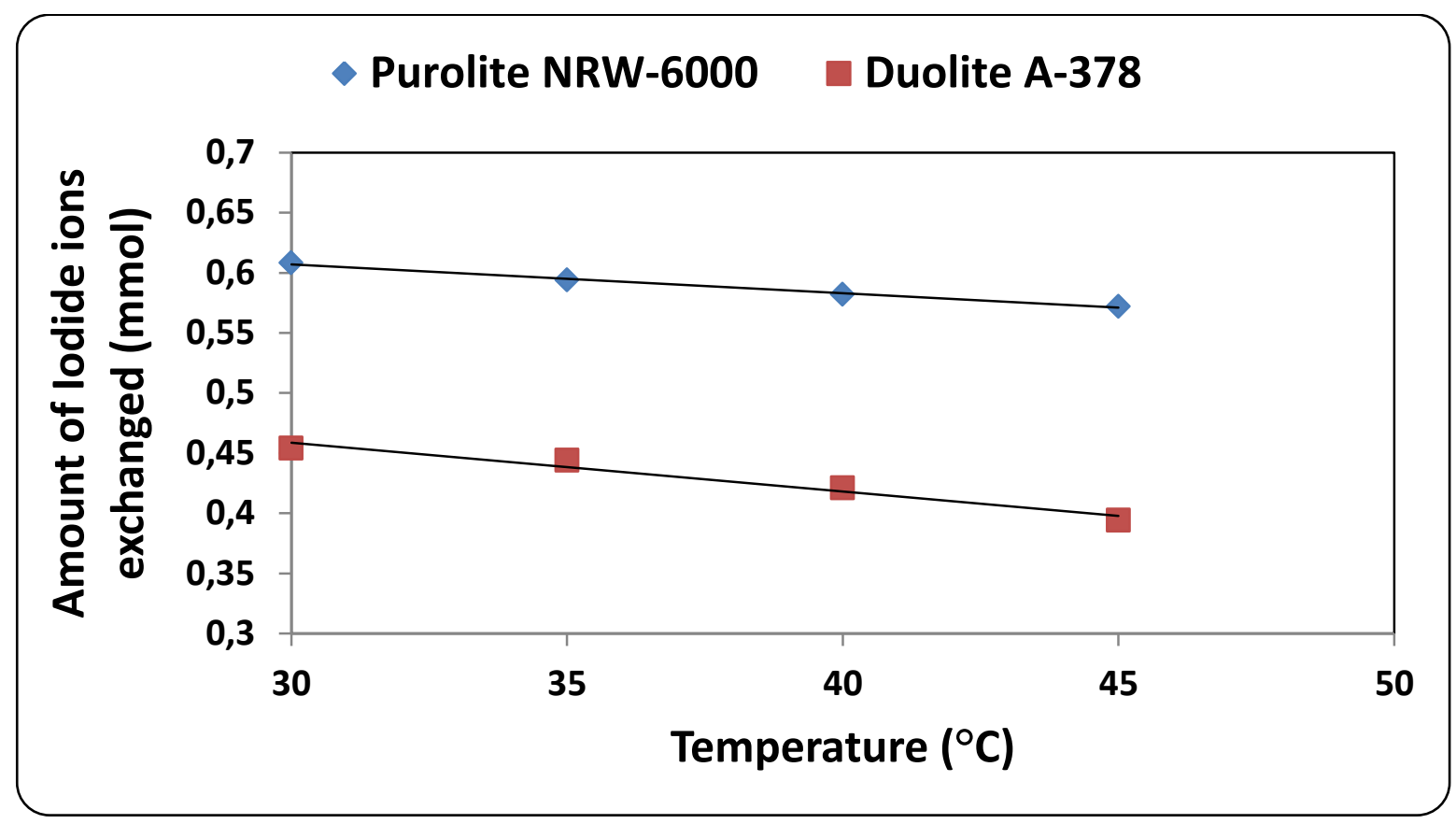

Figure 6. Correlation between Temperature of exchanging medium and amount of iodide ion exchanged.

Amount of ion exchange resin $=1.000 \mathrm{~g}$, Concentration of labeled exchangeable ionic solution $=0.003 \mathrm{~mol} / \mathrm{L}$, Volume of labeled ionic solution $=250 \mathrm{~mL}$, Amount of exchangeable ions in $250 \mathrm{~mL}$ labeled solution $=0.750$ mmol. Correlation coefficient (r) for Purolite NRW-6000 $=-0.9972$ Correlation coefficient ( $\mathrm{r}$ ) for Duolite A-378 $=-0.9820$

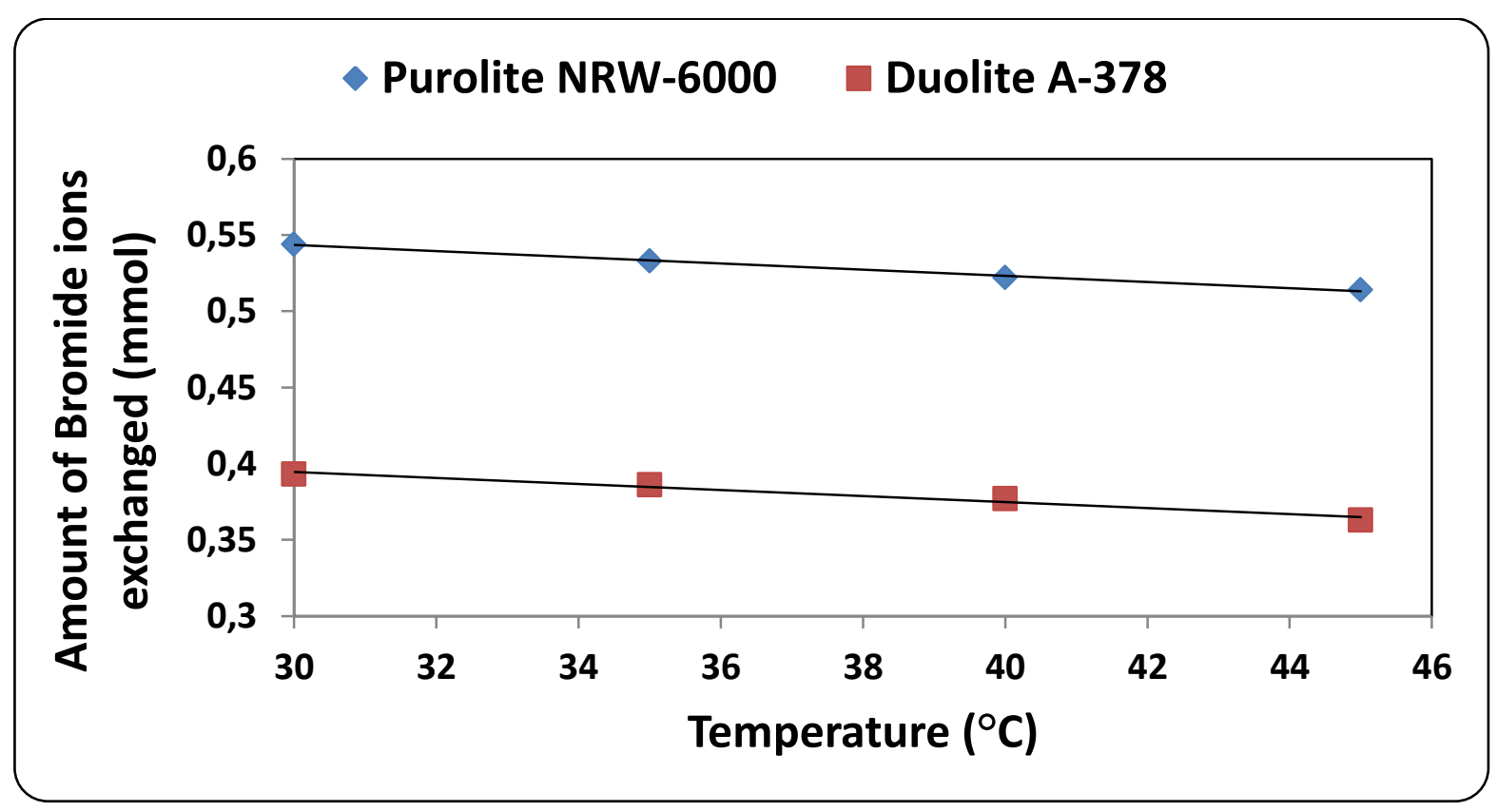

Figure 7. Correlation between Temperature of exchanging medium and amount of bromide ion exchanged.

Amount of ion exchange resin $=1.000 \mathrm{~g}$, Concentration of labeled exchangeable ionic solution $=0.003 \mathrm{~mol} / \mathrm{L}$, Volume of labeled ionic solution $=250 \mathrm{~mL}$, Amount of exchangeable ions in $250 \mathrm{~mL}$ labeled solution $=0.750$ mmol, Correlation coefficient ( $\mathrm{r}$ ) for Purolite NRW-6000 $=-0.9974$

Correlation coefficient ( $\mathrm{r}$ ) for Duolite A-378 $=-0.9873$ 


\section{RESULTS AND DISCUSSION}

\section{1. Comparative study of ion-isotopic exchange reactions}

In the present investigation it was observed that due to the rapid ion-isotopic exchange reaction taking place, the activity of solution decreases rapidly initially, then due to the slow exchange the activity of the solution decreases slowly and finally remains nearly constant. Preliminary studies show that the above exchange reactions are of first order [14-18]. Therefore logarithm of activity when plotted against time gives a composite curve in which the activity initially decreases sharply and thereafter very slowly giving nearly straight line (Figure 1), evidently rapid and slow ion-isotopic exchange reactions were occurring simultaneously [14-18]. Now the straight line was extrapolated back to zero time. The extrapolated portion represents the contribution of slow process to the total activity which now includes rapid process also. The activity due to slow process was subtracted from the total activity at various time intervals. The difference gives the activity due to rapid process only. From the activity exchanged due to rapid process at various time intervals, the specific reaction rates $(k)$ of rapid ion-isotopic exchange reaction were calculated. The amount of iodide / bromide ions exchanged ( $\mathrm{mmol}$ ) on the resin were obtained from the initial and final activity of solution and the amount of exchangeable ions in $250 \mathrm{~mL}$ of solution. From the amount of ions exchanged on the resin $(\mathrm{mmol})$ and the specific reaction rates $\left(\mathrm{min}^{-1}\right)$, the initial rate of ion exchanged $(\mathrm{mmol} / \mathrm{min})$ was calculated.

Because of larger solvated size of bromide ions as compared to that of iodide ions, it was observed that the exchange of bromide ions occurs at the slower rate than that of iodide ions. Hence under identical experimental conditions, the values of specific reaction rate $\left(\mathrm{min}^{-}\right.$ $\left.{ }^{1}\right)$, amount of ion exchanged $(\mathrm{mmol})$ and initial rate of ion exchange $(\mathrm{mmol} / \mathrm{min})$ are calculated to be lower for bromide ion-isotopic exchange reaction than that for iodide ionisotopic exchange reaction as summarized in Tables 3 and 4. For both bromide and iodide ion-isotopic exchange reactions, under identical experimental conditions, the values of specific reaction rate increases with increase in the concentration of iodide and bromide ions in solution from $0.001 \mathrm{~mol} / \mathrm{L}$ to $0.004 \mathrm{~mol} / \mathrm{L}$ (Table 3). However, with rise in temperature from $30.0{ }^{\circ} \mathrm{C}$ to $45.0^{\circ} \mathrm{C}$, the specific reaction rate was observed to decrease (Table 4). Thus in case of Purolite NRW- 6000 at $40.0^{\circ} \mathrm{C}$ when the concentration of iodide and bromide ions in solution increases from $0.001 \mathrm{~mol} / \mathrm{L}$ to $0.004 \mathrm{~mol} / \mathrm{L}$, the specific reaction rate values for iodide ion-isotopic exchange increases from 0.314 to $0.344 \mathrm{~min}^{-1}$, while for bromide ionisotopic exchange the values increases from 0.266 to $0.292 \mathrm{~min}^{-1}$. Similarly in case of Duolite A-378, under identical experimental conditions, the values for iodide ion-isotopic exchange increases from 0.187 to $0.219 \mathrm{~min}^{-1}$, while for bromide ion-isotopic exchange the values increases from 0.156 to $0.172 \mathrm{~min}^{-1}$. However when the concentration of iodide and bromide ions in solution is kept constant at $0.003 \mathrm{~mol} / \mathrm{L}$ and temperature is raised from $30.0{ }^{\circ} \mathrm{C}$ to 45.0 ${ }^{\circ} \mathrm{C}$, in case of Purolite NRW-6000 the specific reaction rate values for iodide ion-isotopic exchange decreases from 0.354 to $0.324 \mathrm{~min}^{-1}$, while for bromide ion-isotopic exchange the values decreases from 0.301 to $0.275 \mathrm{~min}^{-1}$. Similarly in case of Duolite A-378, under identical experimental conditions, the specific reaction rate values for iodide ion-isotopic exchange decreases from 0.227 to $0.196 \mathrm{~min}^{-1}$, while for bromide ion-isotopic exchange the values decreases from 0.190 to $0.155 \mathrm{~min}^{-1}$. From the results, it appears that iodide ions exchange at the faster rate as compared to that of bromide ions which was related to the extent of solvation (Tables 3 and 4).

From the knowledge of $A_{i}, A_{f}$, volume of the exchangeable ionic solution ( $V$ ) and mass of ion exchange resin $(m)$, the $K_{d}$ value was calculated by the equation 


$$
K_{d}=\left[\left(A_{i}-A_{f}\right) / A_{f}\right] \times V / m
$$

Previous studies $[19,20]$ on halide ion distribution coefficient on strong and weak basic anion exchange resins indicate that the selectivity coefficient between halide ions increased at higher electrolyte concentrations. Adachi et al. [21] observed that the swelling pressure of the resin decreased at higher solute concentrations resulting in larger $K_{d}$ values. The temperature dependence of $K_{d}$ values on cation exchange resin was studied by Shuji et al. [22]; were they observed that the values of $\mathrm{K}_{\mathrm{d}}$ increased with fall in temperature. The present experimental results also indicates that the $\mathrm{K}_{\mathrm{d}}$ values for bromide and iodide ions increases with increase in ionic concentration of the external solution, however with rise in temperature the $K_{d}$ values were found to decrease. Thus in case of Purolite NRW-6000 at $40.0{ }^{\circ} \mathrm{C}$ when the concentration of iodide and bromide ions in solution increases from $0.001 \mathrm{~mol} / \mathrm{L}$ to 0.004 $\mathrm{mol} / \mathrm{L}$, the $\log \mathrm{K}_{\mathrm{d}}$ values for iodide ions increases from 14.2 to 17.4 , while for bromide ions the values increases from 8.7 to 10.2. Similarly in case of Duolite A-378, under identical experimental conditions, the $\log \mathrm{K}_{\mathrm{d}}$ values for iodide ions increases from 12.7 to 15.9 , while for bromide ions the values increases from 7.6 to 9.1. However when the concentration of iodide and bromide ions in solution is kept constant at $0.003 \mathrm{~mol} / \mathrm{L}$ and temperature is raised from $30.0{ }^{\circ} \mathrm{C}$ to $45.0{ }^{\circ} \mathrm{C}$, in case of Purolite NRW-6000 the $\log \mathrm{K}_{\mathrm{d}}$ values for iodide ions decreases from 17.2 to 15.9 , while for bromide ions the values decreases from 11.1 to 9.3 . Similarly in case of Duolite A-378, under identical experimental conditions, the $\log \mathrm{K}_{\mathrm{d}}$ values for iodide ions decreases from 15.7 to 14.4 , while for bromide ions the values decreases from 10.0 to 8.2. It was also observed that the $K_{d}$ values for iodide ion-isotopic exchange reaction were calculated to be higher than that for bromide ion-isotopic exchange reaction (Tables 3 and 4).

\section{2. Comparative study of anion exchange resins}

From the Table 3 and 4, it is observed that for iodide ion-isotopic exchange reaction by using Purolite NRW-6000 resin, the values of specific reaction rate $\left(\mathrm{min}^{-1}\right)$, amount of iodide ion exchanged ( $\mathrm{mmol})$, initial rate of iodide ion exchange $(\mathrm{mmol} / \mathrm{min})$ and $\log \mathrm{K}_{\mathrm{d}}$ were 0.332 , $0.582,0.193$ and 16.2 respectively, which was higher than $0.210,0.421,0.088$ and 14.7 respectively as that obtained by using Duolite A-378 resins under identical experimental conditions of $40.0^{\circ} \mathrm{C}, 1.000 \mathrm{~g}$ of ion exchange resins and $0.003 \mathrm{~mol} / \mathrm{L}$ labeled iodide ion solution. The identical trend was observed for the two resins during bromide ion-isotopic exchange reaction.

From Table 3, it is observed that at a constant temperature of $40.0{ }^{\circ} \mathrm{C}$, as the concentration of labeled iodide ion solution increases from $0.001 \mathrm{~mol} / \mathrm{L}$ to $0.004 \mathrm{~mol} / \mathrm{L}$, the percentage of iodide ions exchanged increases from $74.68 \%$ to $79.48 \%$ using Purolite NRW6000 resins and from $52.30 \%$ to $58.90 \%$ using Duolite A-378 resins. Similarly in case of bromide ion-isotopic exchange reactions under identical experimental conditions, the percentage of bromide ions exchanged increases from $67.00 \%$ to $71.16 \%$ using Purolite NRW-6000 resin and from $48.60 \%$ to $51.20 \%$ using Duolite A-378 resin. The effect of ionic concentration on percentage of ions exchanged is graphically represented in Figure 2.

From Table 4, it is observed that for $0.003 \mathrm{~mol} / \mathrm{L}$ labeled iodide ion solution, as the temperature increases from $30.0{ }^{\circ} \mathrm{C}$ to $45.0{ }^{\circ} \mathrm{C}$, the percentage of iodide ions exchanged decreases from $81.08 \%$ to $76.28 \%$ using Purolite NRW-6000 resins and from $60.51 \%$ to $52.58 \%$ using Duolite A-378 resins. Similarly under identical experimental conditions, in case of bromide ion-isotopic exchange reactions, the percentage of bromide ions exchanged decreases from $72.58 \%$ to $68.48 \%$ using Purolite NRW-6000 resin and from $52.39 \%$ to 
$48.46 \%$ using Duolite A-378 resin. The effect of temperature on percentage of ions exchanged is graphically represented in Figure 3.

The overall results indicate that under identical experimental conditions, as compared to Duolite A-378 resins, Purolite NRW-6000 resins shows higher percentage of ions exchanged. Thus Purolite NRW-6000 resins show superior performance over Duolite A-378 resins under identical operational parameters.

\section{3. Statistical Correlations}

The results of present investigation show a strong positive linear correlation between amount of ions exchanged and concentration of ionic solution (Figures 4, 5). In case of iodide ion-isotopic exchange reaction, the values of correlation coefficient $(r)$ were calculated as 0.9998 and 0.9986 for Purolite NRW-6000 and Duolite A-378 resins respectively, while for bromide ion-isotopic exchange reaction, the values of $r$ was calculated as 0.9998 and 0.9999 respectively for the two resins.

There also exist a strong negative correlation between amount of ions exchanged and temperature of exchanging medium (Figures 6, 7). In case of iodide ion-isotopic exchange reactions the values of $r$ calculated for Purolite NRW-6000 and Duolite A-378 resins were 0.9972 and -0.9820 respectively. Similarly in case of bromide ion-isotopic exchange reactions the $r$ values calculated were -0.9974 and -0.9873 respectively for the two resins.

\section{CONCLUSION}

The experimental work carried out in the present investigation will help to standardize the operational process parameters so as to improve the performance of selected ion exchange resins. The radioactive tracer technique used here can also be applied further for characterization of different nuclear as well as non-nuclear grade ion exchange resins.

\section{Acknowledgement}

The author is thankful to Professor Dr. R.S. Lokhande (Retired) for his valuable help and support by providing the required facilities so as to carry out the experimental work in Radiochemistry Laboratory, Department of Chemistry, University of Mumbai, Vidyanagari, Mumbai -58.

\section{References}

[1] Application of Ion Exchange Processes For the Treatment of Radioactive Waste and Management of Spent Ion Exchangers, Technical Reports Series No. 408, International Atomic Energy Agency, Vienna, (2002).

[2] Tomoi M., Yamaguchi K., Ando R., Kantake Y., Aosaki Y., Kubota H., J. Appl. Poly. Sci. 64(6) (1997) 1161-1167.

[3] Zhu L., Liu Y., Chen J., Ind. Eng. Chem. Res. 48(7) (2009) 3261-3267.

[4] Samanta S. K., Ramaswamy M., Misra B. M., Sep. Sci. Technol. 27 (1992) 255-267.

[5] Samanta S. K., Theyyunni T. K., Misra B. M., J. Nucl. Sci. Technol. 32 (1995) 425-429. 
[6] Kumaresan R., Sabharwal K. N., Srinivasan T. G., Vasudeva Rao P. R., Dhekane G., Solvent Extraction and Ion Exchange 24(4) (2006) 589-602.

[7] Deborah L. S., Nazila, K., Douglas B. K., James A. D., Geochemical Transactions 14 (2013) 1 .

[8] Harland C. E., Ion Exchange, DOI: 10.1039/9781847551184-00049, ISBN: 978-0-85186-484-6, eISBN: 978-1-84755-118-4, $2^{\text {nd }}$ Edition, RSC Publishing, UK, pp.49-89, (1994).

[9] Patel S. A., Shah B. S., Patel R. M., Patel P. M., Iranian Polymer Journal 13(6) (2004) 445-453.

[10] Liu H., Zhang S., Nie S., Zhao X., Sun X., Yang X., Pan W., Chem. Pharm. Bull. 53(6) (2005) 631-633.

[11] Masram D. T., Kariya K. P., Bhave N. S., Applied Science Segment 1(1) APS/1513 (2010).

[12] Sood D. D., Reddy A. V. R., Ramamoorthy N., Indian Association of Nuclear Chemists and Allied Scientists, January (2004) 289-297.

[13] Radiotracer Applications in Industry - A Guidebook, Technical Reports Series No. 423, IAEA, Vienna 2004.

[14] Singare P. U., Lokhande R. S., Ionics 18(4) (2012) 351-357.

[15] Lokhande R. S., Singare P. U., Radiochim. Acta 95(03) (2007) 173-176.

[16] Lokhande R. S., Singare P. U., Patil V. V., Radiochemistry 50(06) (2008) 638-641.

[17] Lokhande R. S., Singare P. U., J. Porous Mater 15(03) (2008) 253-258.

[18] Lokhande R. S., Singare P. U., Dole M. H., J. Nuclear and Radiochemical Sciences 7(02) (2006) 29-32.

[19] Heumann K. G., Baier K., Chromatographia 15(11) (1982) 701-703.

[20] Singare P. U., Lokhande R. S., Patil V. V., Prabhavalkar T. S., Tiwari S. R. D., European J. Chemistry 1(1) (2010) 47-49.

[21] Adachi S., Mizuno T., Matsuno R., J. Chromatogr. A 708 (1995) 177-183.

[22] Shuji A., Takcshi M., Ryuichi M., Biosci. Biotechnol. Biochem. 60(2) (1996) 338-340.

[23] Pravin U. Singare, International Letters of Chemistry, Physics and Astronomy 6 (2013) $1-5$.

[24] P. U. Singare, International Letters of Chemistry, Physics and Astronomy 12 (2013) $1-13$.

[25] P. U. Singare, International Letters of Chemistry, Physics and Astronomy 12 (2013) 14-27. 